\title{
Stereotaxic mapping of brainstem areas critical for the expression of the rodent's preference for the dark
}

\author{
ROBERT THOMPSON and JOSEPH E. LEDOUX \\ Louisiana State University, Baton Rouge, Louisiana 70803
}

Different groups of adult rats were subjected to discrete lesions in one of 36 different areas of the brain and were subsequently tested for the rodent's predictable preference for the dark. Deficient preference scores were observed in those groups having damage to the occipito-temporal cortex, cingulate cortex, dorsal hippocampus, anterior hypothalamus, dorsomedial thalamus, posterior thalamus, midbrain reticular formation, interpedunculo/central-tegmental area, or pontine reticular formation. These results were plotted on the Massopust (1961) atlas.

In an earlier study (Thompson \& LeDoux, 1974), the integrity of the rodent's preference for a small dark compartment over a large illuminated compartment was examined in the presence of lesions to several different parts of the neocortex and brainstem. In the interim, we have expanded the size of the groups examined earlier and have broadened the number of brain regions investigated. In the current paper, a detailed description of the critical brainstem (and telencephalic) areas necessary for the expression of this species-predictable visual preference will be given in the form of a stereotaxic map.

\section{METHOD}

Adult male albino rats of the Wistar strain were used. The majority sustained bilateral cortical or subcortical lesions 10 to 20 days prior to testing. The size of the lesions investigated in this experiment was comparable to those reported in a recent study which also canvassed many different cortical and subcortical structures with lesions (Thompson, 1974). During the postsurgical period, each rat was handled and its behavior periodically observed on a black Masonite table. Food and water were available in the home cage at all times.

The apparatus consisted of a differentially illuminated twocompartment box which has been fully described elsewhere (Thompson \& LeDoux, 1974). The test consisted of placing the rat into the illuminated compartment and observing the subject for $10 \mathrm{~min}$. The latency to enter the dark compartment (scored when the subject placed all four feet within the threshold), the number of exits from the dark compartment, and the total time spent in the dark compartment were recorded. Since the latency measures have been reported earlier (Thompson \& LeDoux, 1975), only the results concerning the remaining two measures will be discussed.

\section{RESULTS}

Table 1 presents the percentage of time spent in the dark compartment (after initial entry into that compart-

This research was supported in part by a grant from the Graduate Council on Research, Louisiana State University.
Table 1

Mean Preference Scores for All Groups

\begin{tabular}{|c|c|c|c|}
\hline Group & $\mathrm{N}$ & $\begin{array}{c}\% \text { Time } \\
\text { in Dark } \\
\text { Compart- } \\
\text { ment }\end{array}$ & $\begin{array}{l}\mathrm{N} \text { of } \\
\text { Exits }\end{array}$ \\
\hline Control (sham operated) & 25 & 93.3 & 2.2 \\
\hline Blind & 12 & $33.2 *$ & $7.3^{*}$ \\
\hline Olfactory bulb & 5 & 95.5 & 2.4 \\
\hline Fronto-parietal cortex & 5 & 97.7 & .4 \\
\hline Occipito-temporal cortex & 5 & $55.2^{*}$ & 6.2 \\
\hline Decorticate & 14 & 91.9 & 3.6 \\
\hline Cingulate cortex & 9 & $77.4 *$ & $6.7^{*}$ \\
\hline Caudoputamen & 5 & 89.3 & 3.0 \\
\hline Globus pallidus & 4 & 93.9 & 1.8 \\
\hline Entopeduncular area & 4 & 94.6 & 2.2 \\
\hline Septal area & 7 & 94.1 & 3.2 \\
\hline Dorsal hippocampus & 8 & $78.5^{*}$ & $10.3^{*}$ \\
\hline Amygdala & 7 & 89.0 & 4.8 \\
\hline Anteromedial hypothalamus & 7 & $62.9 *$ & $12.0^{*}$ \\
\hline Anterolateral hypothalamus & 6 & 96.9 & .2 \\
\hline Posteromedial hypothalamus & 5 & 89.1 & .8 \\
\hline Posterolateral hypothalamus & 4 & 95.0 & .5 \\
\hline Mammillary bodies & 3 & 100 & 0 \\
\hline Anterior thalamus & 7 & 89.9 & 5.1 \\
\hline Ventromedial thalamus & 4 & 85.0 & 3.8 \\
\hline Dorsomedial thalamus & 8 & $75.9 *$ & 6.4 \\
\hline Lateral thalamus & 5 & 86.5 & 3.4 \\
\hline Ventral thalamus & 5 & 88.0 & 4.2 \\
\hline Posterior thalamus & 8 & $66.2 *$ & 3.3 \\
\hline Subthalamus & 11 & 82.4 & 4.1 \\
\hline Ventral tegmental area & 3 & 100 & 0 \\
\hline Substantia nigra & 6 & 80.0 & 4.8 \\
\hline Red nucleus & 6 & 83.3 & 4.8 \\
\hline Central tegmental area & 5 & $63.5^{*}$ & $18.5^{*}$ \\
\hline Median raphe & 4 & $44.6^{*}$ & $12.0 *$ \\
\hline Superior colliculus & 6 & 88.0 & 4.0 \\
\hline Inferior colliculus & 4 & 94.3 & 3.8 \\
\hline Mesodiencephalic reticular formation & 6 & $62.9 *$ & 6.0 \\
\hline Prerubral reticular formation & 3 & 100 & 0 \\
\hline \multicolumn{4}{|l|}{ Mesencephalic reticular formation } \\
\hline Dorsal & 5 & $70.5^{*}$ & $9.5^{*}$ \\
\hline Lateral & 10 & 85.2 & 4.5 \\
\hline Caudal & 5 & 80.8 & 4.8 \\
\hline Pontine reticular formation & 6 & $62.3^{*}$ & 8.3 \\
\hline Cerebellum & 4 & 100 & 0 \\
\hline
\end{tabular}

${ }^{*} p<.05$ (Mann-Whitney U test) 
ment) and the number of exits from the dark compartment for all groups. ${ }^{1}$ Of the 37 brain-damaged groups involved, only 11 showed a significant depression in the percent time spent in the dark compartment. With only a few exceptions, the 11 groups also exhibited a significant elevation in the number of exits from the dark compartment.

Mapping the critical areas for this depression in the preference for the dark compartment was based upon the distribution of lesions sustained by subjects that obtained preference scores below $70 \%$; the poorest sham-operated control animal earned a preference score of $70.6 \%$. (All of the brain-damaged subjects were derived from groups that were significantly different from the controls.) As shown in the top panel of Figure 1, the critical subcortical areas extend from the pontine reticular formation to the medial preoptic hypothalamus. The critical cortical areas include the occipito-temporal region (bottom left panel of Figure 1) and the cingulate region (bottom right panel of Figure 1).

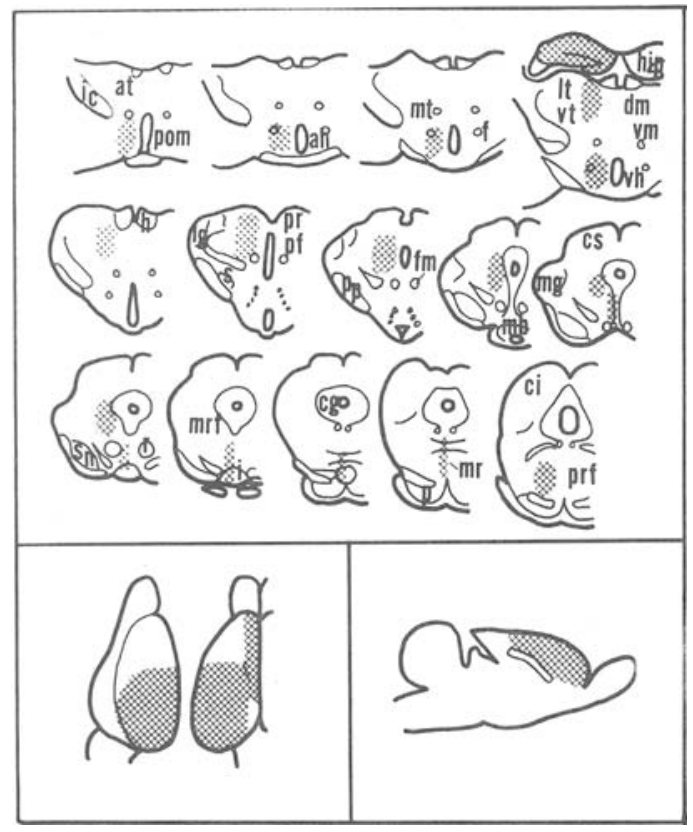

Figure 1. Critical cortical (bottom two panels) and subcortical (top panel) areas (cross-hatched) for the expression of the rat's preference for the dark. The 14 frontal sections through the brainstem, which are spaced approximately $.5 \mathrm{~mm}$, are based upon the rat atlas of Massopust (1961). Abbreviations: at $=$ anterior thalamus, $\mathrm{cg}=$ central gray, $\mathrm{ci}=$ inferior colliculus, cs $=$ superior colliculus, $\mathrm{dm}=$ dorsomedial thalamus, $f=$ fornix column, $\mathrm{fm}=$ habenulopenduncular tract, $\mathrm{h}=$ habenula, hip = hippocampus, ic $=$ internal capsule, $i=$ interpeduncular nucleus, lt $=$ lateral thalamus, $\mathrm{mb}=$ mammillary bodies, $\mathrm{mg}=$ medial geniculate nucleus, $\mathrm{mr}=$ median raphe, $\mathrm{mrf}=$ midbrain reticular formation, $\mathrm{mt}=$ mammillothalamic tract, $\mathrm{p}=$ pons, $\mathrm{pf}=$ parafascicular nucleus, pom $=$ medial preoptic hypothalamus, $\mathrm{pp}=$ cerebral peduncle, $\mathrm{pr}=$ pretectal area, prf $=$ pontine reticular formation, $r=$ red nucleus, $s=$ subthalamic nucleus, $s n=$ substantia nigra, $\mathbf{v m}=$ ventromedial thalamus, $\mathrm{vh}=$ ventromedial hypothalamic nucleus, $\mathrm{vt}=$ ventral thalamus.

\section{DISCUSSION}

Under short-term testing conditions, the appearance of the rodent's preference for a small dark compartment over a large illuminated compartment seems to be dependent upon the integrity of a number of brainstem and telencephalic structures. The distribution of the critical brainstem areas shown in Figure 1 suggests the existence of a "pathway" between the pontine reticular formation and the medial preoptic hypothalamus which may participate either directly or indirectly in the expression of the rodent's preference for the dark. This pathway, however, does not resemble that associated with learned visualdiscrimination performance (Thompson, 1976), nor does it closely parallel any of the recently described chemical pathways of the rat brain (Jacobowitz \& Palkovits, 1974; Palkovits \& Jacobowitz, 1974).

At the present time, it would be treacherous to conclude that the critical areas shown in Figure 1 mediate the rodent's predictable preference for the dark (or aversion to the light) for three reasons. First, a portion of our results (particularly those dealing with the occipito-temporal cortex and the posterior thalamus) are not consistent with those reported recently by Whishaw (1974), who monitored the behavior of rats over a long period of time in a differentially illuminated two-compartment box. These inconsistencies would suggest that the results of the current study may be situation specific and, therefore, of limited generality in relation to the brain mechanisms underlying the rat's preference for the dark. Second, the possibility must be considered that the diminished preference for the dark exhibited by rats sustaining lesions to some (or all) of the areas depicted in Figure 1 is a consequence of increased activity levels. The data on the number of exits from the dark compartment could be interpreted as supporting this possibility. Finally, our results dealing with the ablation of various portions of the neocortex suggest the existence of two opposing systems (excitatory and inhibitory) within the brain which must be in dynamic equilibrium before the normal expression of this species-predictable preference can occur. This suggestion comes from a comparison of the preference scores earned by the three groups having occipito-temporal, frontalparietal, and virtually total neocortical ablations: The former group showed depressed preference scores, ${ }^{2}$ the intermediate group showed heightened preference scores, and the latter group showed essentially normal preference scores. This pattern of results is reminiscent of the findings of Lubar (1964), Vanderwolf (1964) and many others in showing that a second lesion superimposed upon an initial lesion may attenuate or even eliminate the deficit produced by the initial lesion.

\section{REFERENCES}

Jacobowitz, D. M., \& Palkovits, M. Topographic atlas of catecholamine and acetylcholinesterase-containing neurons in the rat brain. Journal of Comparative Neurology, 1974, $157,13-28$.

KRIEG, W. J. S. Connections of the cerebral cortex: I. The albino rat: A. Topography of the cortical areas. Journal of Comparative Neurology, 1946, 84, 221-275.

LUBAR, J. F. Effect of medial cortical lesions on the avoidance behavior of the cat. Journal of Comparative and Physiological Psychology, 1964, 58, 38-46.

Massopust, L. C. Stereotaxic atlases: A. Diencephalon of the rat. In D. E. Sheer (Ed.), Electrical stimulation of the brain. Austin: University of Texas Press, 1961.

Palkovits, M., \& Jacobowitz, D. M. Topographic atlas of catecholamine and acetylcholinesterase-containing neurons in the rat brain. Journal of Comparative Neurology, 1974, 157, 29-42.

Thомpson, R. Localization of the "maze memory system" in the white rat. Physiological Psychology, 1974, 2, 1-17. 
Thомpson, R. Stereotaxic mapping of brainstem areas critical for memory of visual discrimination habits in the rat. Physiological Psychology, 1976, 4, 1-10.

Thompson, R., \& LEDoux, J. E. Common brain regions essential for the expression of learned and instinctive visual habits in the albino rat. Bulletin of the Psychonomic Society, 1974, 4, 78-80.

Thompson, R., \& LeDoux, J. E. A stereotaxic map of brainstem areas critical for locomotor responses in a novel environment. Bulletin of the Psychonomic Society, 1975, 6, 327-328.

VANDERWOLF, C. H. Effect of combined medial thalamic and septal lesions on active-avoidance behavior. Journal of Comparative and Physiological Psychology, 1964, 58, 31-37.

WhishaW, I. Q. Light avoidance in normal rats and rats with primary visual system lesions. Physiological Psychology, 1974, 2, 143-147.

\section{NOTES}

1. The performance of the group blinded by enucleation suggests that the nonblind control animals preferred the small dark compartment because of its darkness, not because of its smallness.

2. This group sustained bilateral lesions destroying at least $85 \%$ of Areas 17,18 , and 18a of Krieg (1946). An additional group of six animals having smaller lesions to the occipitotemporal cortex (averaging approximately 60\% damage to Areas 17, 18, and 18a) earned essentially normal preference scores. 